\title{
Halogen free, acrylate based/nano bentonite composite functionally validated insulator for electric conductors
}

\begin{abstract}
Poly (methyl methacrylate-butyl acrylate-acrylic acid)/nano bentonite 34 and Cloisite 20 A composites were prepared through bulk polymerization in presence of BPO (benzoyl peroxide) as initiator. The polymer/nano bentonite composite sheets were molded at $180^{\circ} \mathrm{C}$ prior subjecting to the specific mechanical and electrical characterization. Structural, physical and thermal validations were conducted through GPC, FT-IR, XRD and HRTEM and TGA classified techniques. The results of the electrical resistivity and mechanical properties aptitudes signpost step towards a new generation of halogen free insulators for electrical cables according to IEC 60502 and BS7655 standards.
\end{abstract}

Keywords: Poly (methyl methacrylate-butyl acrylate-acrylic acid), bentonite 34, cloisite $20 \mathrm{~A}$, halogen free insulators for electrical cables
Volume 2 Issue 7 - 2017

\author{
MF Afify,' MA Mekewi, ${ }^{2}$ MA Abd El Ghaffar, ${ }^{3}$ \\ SH Elmossalamy, ${ }^{2}$ EAM Youssef, M Abd Elhay ${ }^{2}$ \\ 'Egyptian Company for plastic industries, Egypt \\ ${ }^{2}$ Department of Chemistry, Ain Shams University Cairo, Egypt \\ ${ }^{3}$ Department of Polymers and Pigments, National Research \\ Centre, Egypt
}

Correspondence: MF Afify, Egyptian Company for plastic Industries, Egypt, Email chemist.m.fahmy@gmail.com

Received: July 20, 2017 | Published: September I5, 2017
Abbreviations: GPC; gel permeation chromatography; FTIR, fourier transform infra red; XRD, X ray diffraction; HRTEM, High Resolution Transmission Electron Microscopy; TGA, thermo gravimetric analysis; IEC 60520; international electronic commission number 60520; BS 7655; british standard number 7655, PMMA, poly methyl methacrylate; PC, Poly Carbonate; PBA, poly butyl acrylate; PP, poly propylene; PVC, poly vinyl chloride; NBR, n i t rile butadiene rubber; BA, butyl acrylate; MMA, methyl methacrylate; AA, acrylic acid; EPDM; ethylene propylene diene monomer, BPO; benzoyl peroxide; $\mathrm{Tg}$, glass transition temperature; Wt. \%, weight percent; ASTMD1248-98, american society for testing and materials number 1248-98

\section{Introduction}

Electric power cables are made of stranded copper or aluminum conductors. As copper metal acquires higher conductivity than aluminum it is more commonly employed for the cables make being more ductile and of relatively high tensile strength. Rather, copper is more expensive and denser than aluminum but still favored. ${ }^{1}$ Halogen free cables are becoming increasingly necessary to protect against the risk of toxic gas emissions during combustion. This type of cabling is increasingly of relevance in public sector housing and major new developments. $^{2}$

Poly (methyl methacrylate), PMMA, is one of the most widely used types of acrylate polymers due to its favorable clarity and outstanding outdoor weathering resistance, easy handling, processing, and low cost. These impressive properties made PMMA preferred economically to polycarbonates (PC) when a high strength quality is not critical. However, PMMA usually behaves in a brittle manner when loaded, resulting in its restricted application. To overcome functional risking aspects, copolymerization of MMA with other specified monomers that aid glass transition temperature (Tg) alleviation to below room temperature, e.g., butyl acrylate polymers (PBA) are exploited. Generally, the PBA is considered as a colorless transparent rubbery polymer at ambient temperature, thus, it is commonly used in copolymer systems to lighten, also, the brittleness of the final product. ${ }^{3}$ Polymer/silicate nanocomposites are proposed as a novel class of composites due to their higher mechanical advantages, proved gas barrier, flame retardation etc. ${ }^{4}$ Among such validated silicates is the bentonite which was exercised with the PMMA matrix ${ }^{5,6}$ acrylate polymers, ${ }^{7,8} \mathrm{NBR} / \mathrm{PVC},{ }^{9} \mathrm{PP} / \mathrm{EPDM}^{10}$ and PVC. ${ }^{11}$ The efficiency of bentonite to modify the properties of the polymer depends primarily on the degree of its dispersion in the polymeric matrix and its compatibility. ${ }^{12}$ The objective of this work is to improve the physical, electrical, thermal and mechanical properties of PMMA copolymers/ nano bentonite composites to design a valid, compatible and opportune halogen free electrical insulation that satisfies measurable specified properties of cable insulators compared to currently used formulations.

\section{Experimental}

\section{Materials}

Acrylic acid was used without further purification was supplied by Fine-Chemicals LTD Company, butyl acrylate monomer was provided by Sigma Aldrich, and methyl methacrylate by Alfa Aesar. The methyl methacrylate and butyl acrylate monomers were activated prior use by shaking several times with $5 \% \mathrm{NaOH}$ solution, to remove the stabilizer and then washed by distilled water several times until neutrality. The freshly inhibitor-free monomer was then distilled under vacuum and finally kept under $\mathrm{Na}_{2} \mathrm{SO}_{4}$ anhydrous. The refractive index of the inhibitor-free monomers was measured to affirm its purity prior use. Benzoyl peroxide as initiator was provided by Merck-schuchardt.

Cloisite 20 A (organically modified layered magnesium aluminum silicate platelets in nano scale) was provided by BYK for additives and instruments, Germany and Bentonite 34 (organically modified clay) was provided by ELEMENTIS specialties, USA were used at different ratio as fillers.

\section{The polymerization process}

Different ratio of inhibitor-free methyl methacrylate, butyl acrylate, acrylic acid monomers were mixed in dry glass ampoules. 
$\mathrm{BPO}$, as initiator, was then added at $0.6 \%$ by weight in addition to different wt. percent of Cloisite 20 or bentonite 34, as filling material, and as given in Table 1. The glass ampoules were sealed under flow of purified and dry nitrogen gas, then placed in water bath at $60-70^{\circ} \mathrm{C}$ for 4 hours, then left to cool to ambient temperature and finally broken to release its contents and molded at $180^{\circ} \mathrm{C}$.

Table I Formulation of copolymer samples

\begin{tabular}{llll}
\hline \multicolumn{2}{l}{ Monomer \% (By weight) } & \multicolumn{2}{c}{ Filler \% (By Weight) } \\
\cline { 1 - 3 } $\begin{array}{l}\text { Butyl } \\
\text { acrylate }\end{array}$ & $\begin{array}{l}\text { Methyl } \\
\text { methacrylate }\end{array}$ & $\begin{array}{l}\text { Acrylic } \\
\text { acid }\end{array}$ & \\
\hline $45 \%$ & $50 \%$ & $5 \%$ & Zero \\
$45 \%$ & $50 \%$ & $5 \%$ & $1 \%$ Cloisite 20 A \\
$45 \%$ & $50 \%$ & $5 \%$ & $3 \%$ Cloisite 20 A \\
$45 \%$ & $50 \%$ & $5 \%$ & $5 \%$ Cloisite $20 \mathrm{~A}$ \\
$45 \%$ & $50 \%$ & $5 \%$ & $7 \%$ Cloisite $20 \mathrm{~A}$ \\
$45 \%$ & $50 \%$ & $5 \%$ & $10 \%$ Cloisite $20 \mathrm{~A}$ \\
$45 \%$ & $50 \%$ & $5 \%$ & $1 \%$ bentonite 34 \\
$45 \%$ & $50 \%$ & $5 \%$ & $3 \%$ bentonite 34 \\
$45 \%$ & $50 \%$ & $5 \%$ & $5 \%$ bentonite 34 \\
$45 \%$ & $50 \%$ & $5 \%$ & $7 \%$ bentonite 34 \\
$45 \%$ & $50 \%$ & $5 \%$ & $10 \%$ bentonite 34 \\
\hline
\end{tabular}

Characterization of Polymer/Nano Bentonite Composites

\section{Molecular weight determination}

The molecular weights of polymer blend samples using $45 \%$ butyl acrylate, $50 \%$ methyl methacrylate and 5\% acrylic acid monomers in absence and presence of bentonite 34 or Cloisite $20 \mathrm{~A}$, as fillers, were determined using Gel Permeation Chromatography using tetrahydrofuran as the mobile phase Table 2, shows that, the weight average molecular weight $\left(\mathrm{M}_{\mathrm{w}}\right)$ and number average molecular weight $\left(\mathrm{M}_{\mathrm{n}}\right)$ in absence of the filling material are $3.5206 \times 10^{5}$ and $6.0933 \times 10^{4}$ respectively with a degree of Polydispersity $(\mathrm{PD}) \cong 5.78$ which confirms an obvious disorder due to a free radical mechanism influence. In the presence of bentonite 34 , as a filling material, both the weight average and number average molecular weights fluctuate up and down accompanied by a lower value of dispersity index depending on the percentage of bentonite 34 used, Figures $1 \mathrm{a}, 1 \mathrm{~b} \&$ $1 \mathrm{c}$, affirming an intervening role played by the filler to an interfering ionic polymerization mechanism that aids a more stereo-regular polymeric chains compacts.

The same trend was observed when using Cloisite 20 instead of bentonite 34 with nearly the same molecular weight values, Table 3 and Figures $1 \mathrm{a}, 1 \mathrm{~b} \& 1 \mathrm{c}$. The highest value of weight average and number average molecular weights were obtained when using $5 \%$ of bentonite $34\left(4.8036 \times 10^{5}\right.$ and $\left.1.4202 \times 10^{5}\right)$ or Cloisite $20\left(4.7335 \times 10^{5}\right.$ and $\left.1.5281 \times 10^{5}\right)$ with a much lower in the degree of dispersity $(\cong 3.4$ and 3.1) respectively.

This is indicating that both Bentonite 34 and Cloisite 20 A acquire the same role through the polymerization process by acceleration of propagation step through a probable cationic mechanism that aids improving molecular weight distribution (lower PD values). Two parallel mechanisms were suggested by D Njopwouo et al. ${ }^{13}$ For polymerization reaction in the presence of bentonite and acrylic acid who could explain the PD improvement values.

Table 2 Effect of bentonite 34, on the weight average molecular weight, the number average molecular weight and the Polydispersity of BA/MMA/AA polymer blends

\begin{tabular}{llll}
\hline Bentonite 34 filler ratio & $\overline{M_{w}}$ & $\overline{M_{n}}$ & PD \\
\hline- & $3.5206 \times 10^{5}$ & $6.0933 \times 10^{4}$ & 5.7778 \\
$1 \%$ & $2.3759 \times 10^{5}$ & $6.9852 \times 10^{4}$ & 3.4014 \\
$3 \%$ & $1.9584 \times 10^{5}$ & $3.8487 \times 10^{4}$ & 5.0884 \\
$5 \%$ & $4.8036 \times 10^{5}$ & $1.4202 \times 10^{5}$ & 3.3823 \\
$7 \%$ & $2.9605 \times 10^{5}$ & $7.8717 \times 10^{4}$ & 3.7609 \\
$10 \%$ & $3.4329 \times 10^{5}$ & $7.7850 \times 10^{4}$ & 4.4096
\end{tabular}

Table 3 Effect of Cloisite 20 on the weight average molecular weight, the number average molecular weight, and the Polydispersity of BA/MMA/AA polymer blends

\begin{tabular}{llll}
\hline Cloisite 20 filler ratio & $\overline{M_{w}}$ & $\overline{M_{n}}$ & PD \\
\hline- & $3.5206 \times 10^{5}$ & $6.0933 \times 10^{4}$ & 5.7778 \\
$1 \%$ & $2.4799 \times 10^{5}$ & $6.8832 \times 10^{4}$ & 3.6028 \\
$3 \%$ & $2.1120 \times 10^{5}$ & $3.9567 \times 10^{4}$ & 5.3357 \\
$5 \%$ & $4.7335 \times 10^{5}$ & $1.5281 \times 10^{5}$ & 3.0976 \\
$7 \%$ & $3.1155 \times 10^{5}$ & $7.9927 \times 10^{4}$ & 3.8979 \\
$10 \%$ & $3.2338 \times 10^{5}$ & $7.8860 \times 10^{4}$ & 4.1006 \\
\hline
\end{tabular}

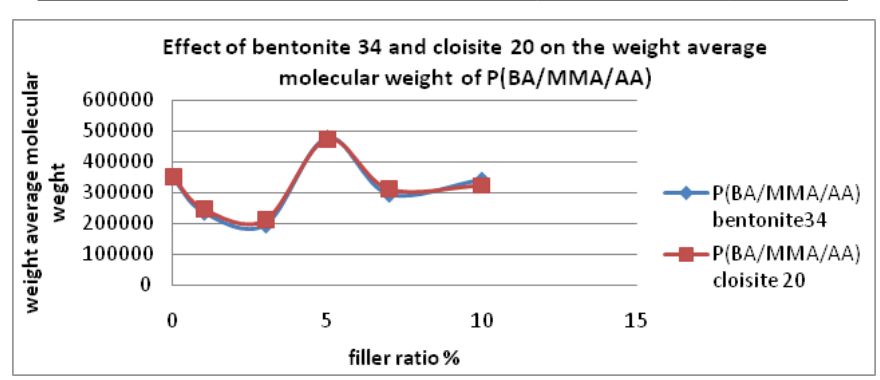

Figure IA Effect of bentonite 34 and Cloisite 20 on the weight average molecular weight of $\mathrm{P}(\mathrm{BA} / \mathrm{MMA} / \mathrm{AA})$.

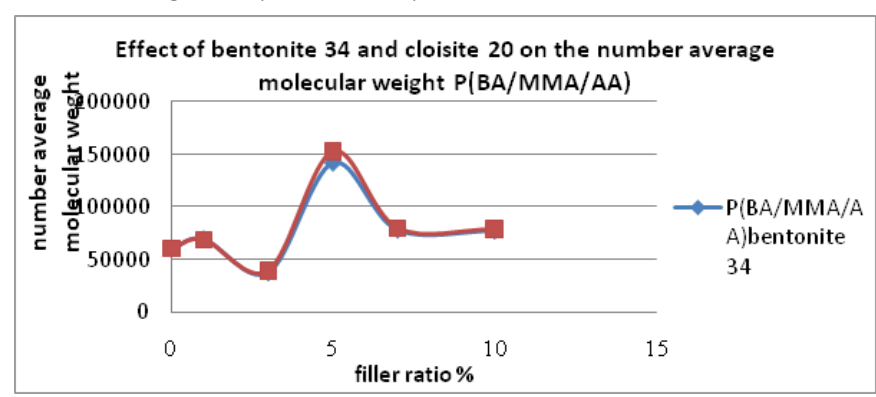

Figure IB Effect of bentonite 34 and Cloisite 20 on the number average molecular weight of $\mathrm{P}(\mathrm{BA} / \mathrm{MMA} / \mathrm{AA})$. 


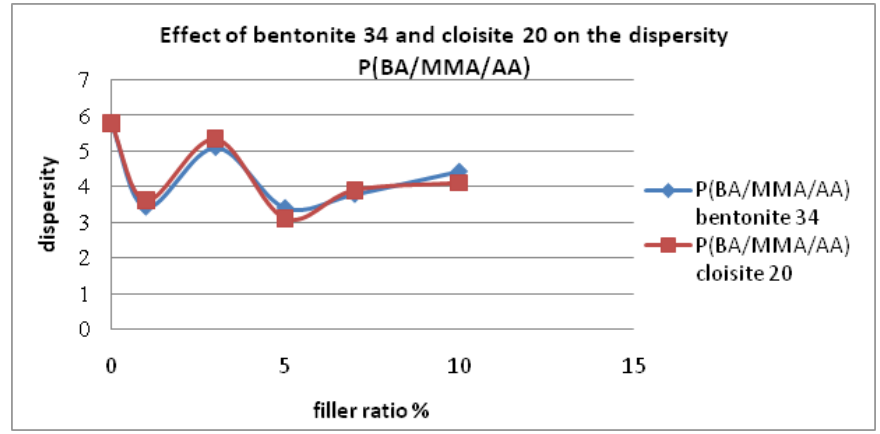

Figure IC Effect of bentonite 34 and Cloisite 20 on the dispersity of $\mathrm{P}(\mathrm{BA} /$ MMA/AA).

\section{Chemical structural justification (FT-IR spectroscopy)}

The accomplishment of the polymerization process in absence and presence of Bentonite 34 or Cloisite 20, as a filling material, was declared through infrared spectroscopy. The FT-IR spectra of Bentonite 34 and Cloisite 20 are shown in Figures 2a, Figure 2b. The absorption bands prevailed at $3630 \mathrm{~cm}^{-1}$ and $916 \mathrm{~cm}^{-1}$ are attributed to $\mathrm{Al}-\mathrm{OH}$ stretching and bending vibration. The band at $625 \mathrm{~cm}^{-1}$ ascribing the Si-O-Al bond, two absorption bands at $463 \mathrm{~cm}^{-1}$ and $522 \mathrm{~cm}^{-1}$ are assigned to low frequency Si-O bending vibration. For the quaternary ammonium salt, two characteristic absorption bands at 2850 and $2920 \mathrm{~cm}^{-1}$ are assigned to the $\mathrm{C}-\mathrm{H}$ stretching vibration of $-\mathrm{CH}_{3}$ and $-\mathrm{CH}_{2}$ groups respectively and the $\mathrm{C}-\mathrm{N}$ stretching vibration band at $1045 \mathrm{~cm}^{-1}$ is also assigned. This is in addition to the absorption corresponding to $v\left(\mathrm{~N}^{+} \mathrm{HCl}^{-}\right)$band. FT-IR spectra of butyl acrylate/ methyl methacrylate/acrylic acid polymer blend is exhibited in Figure 2c.

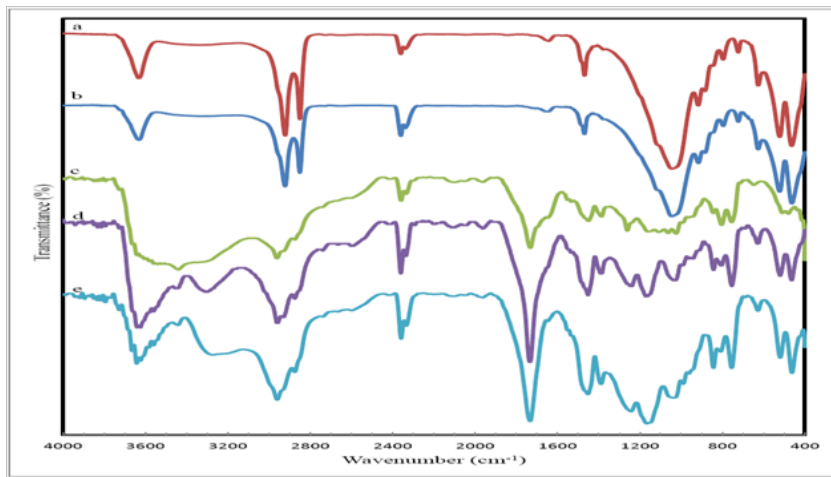

Figure 2 (A) FT-IR spectrum of Cloisite $20 \mathrm{~A}$, (B) FT-IR spectrum of bentonite 34 , (C) FT-IR spectrum of $P(B A / M M A / A A)$, (D) FT-IR spectrum of $P(B A / M M A /$ AA)/bentonite 34, (E) FT-IR spectrum of $P(B A / M M A / A A) / c l o i s i t e ~ 20 A$.

The copolymer blend characteristic absorption bands are shown at $1730 \mathrm{~cm}^{-1}$, which is attributed to $-\mathrm{C}=\mathrm{O}$ stretching vibration, while bands at $2875,2960 \mathrm{~cm}^{-1}$ can be assigned to the $-\mathrm{C}-\mathrm{H}$ stretching vibration of $-\mathrm{CH}_{3}$ and $-\mathrm{CH}_{2}$ groups.

The $-\mathrm{C}-\mathrm{H}$ in-plane bending vibration of $-\mathrm{CH}_{3}$ and $-\mathrm{CH}_{2}$ groups appear at 1392 and $1450 \mathrm{~cm}^{-1}$. The-C-O-C single bond stretching vibration and single bond deformation vibration bands appear at 1260 $\mathrm{cm}^{-1}$ and $844 \mathrm{~cm}^{-1}$ respectively which is the characteristic bands for poly (methyl methacrylate) and poly (butyl acrylate). The indicative band of the $-\mathrm{OH}$ stretching vibration (broad) as characteristic for the polyacrylic acid is developed at $3400 \mathrm{~cm}^{-1}$. The FT-IR spectra of the same polymer blends in presence of bentonite 34 or Cloisite 20, are represented in Figures 2d, Figure 2e. The spectra profile proves the disappearance of the-C-N stretching vibration band at $1045 \mathrm{~cm}^{-1}$, while the disappearance of broad band of $-\mathrm{OH}$ stretching vibration is clearly observed. The instinct absorption of $-\mathrm{C}=\mathrm{O}$ stretching vibration at $1730 \mathrm{~cm}-{ }^{-1}$, the $-\mathrm{C}-\mathrm{H}$ in-plane bending vibration of $-\mathrm{CH}_{3}$ and $-\mathrm{CH}_{2}$ groups appear distinctively at $1387,1450 \mathrm{~cm}^{-1}$ which affirm polymer blend prevalence.

Usually, probable polymers stereo-regularity elevation due to the involvement of an ionic mechanism could be argued from the FTIR spectra but, unfortunately, could not be affirmed due to polymers elapsed absorption bands.

\section{Microstructure relevance (HRTEM imaging)}

The HRTEM microstructure of nano bentonites are exhibited in Figures $3 \mathrm{a}$, Figure $3 \mathrm{~b}$ where the regular sheet structure is clearly demonstrated.

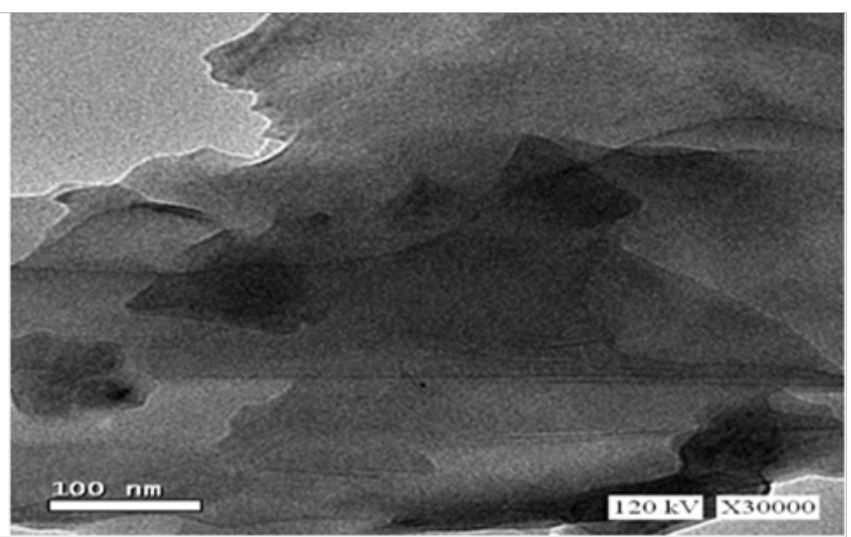

Figure 3A TEM micrograph of Cloisite $20 \mathrm{~A}$.

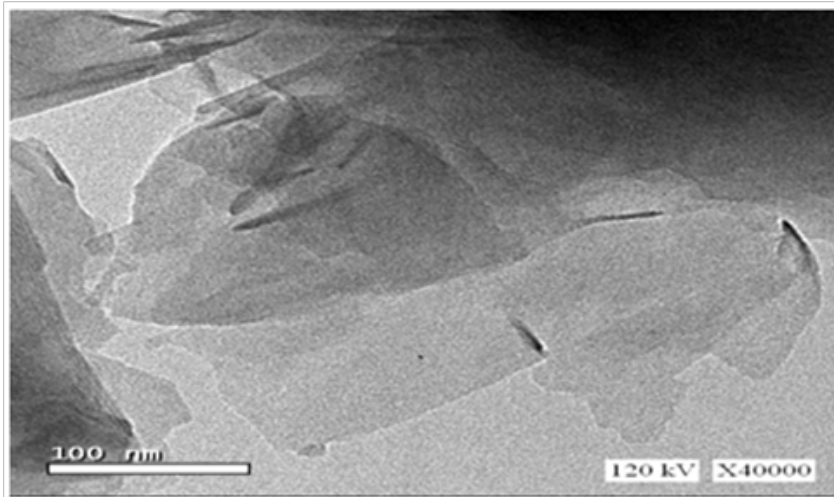

Figure 3B TEM micrograph of bentonite 34 .

Upon copolymerization and in presence of the bentonite, the polymeric matrix offered, at set weight ratios, tendency to allocate the bentonite nano particles in a simulated intercalated layer rather than an exfoliated pattern as clearly indicated by the pattern shown in Figure 3c. The intercalated structure deployed seems to have been encouraged by the presence of the basicity of the filler material that enhanced a selective polymerization mechanism. Such intercalation could be principally assigned to the improvements observed to both the mechanical and electrical properties of the polymer composite in addition to its thermal and anti-degradation aspects. 
The black lines are described as the cross section of aluminosilicate platelets, the platelets seen as single and uniformly dispersed, which aids activating the polymerization process within the bentonite laminar forming a probable inorganic-organic hybrid.

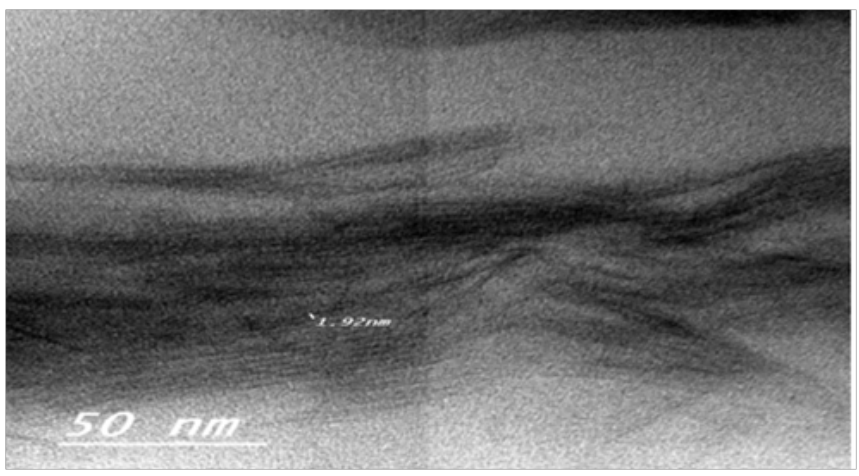

Figure 3C TEM micrographs of (BA/MMA/AA)/bentonite 34.

\section{XRD studies}

The XRD patterns of Cloisite $20 \mathrm{~A}$ and Bentonite 34 are shown in Figures $4 \mathrm{a}$, Figure $4 \mathrm{~b}$. The crystalline peak corresponded to 001 plane of Cloisite $20 \mathrm{~A}$ is at $2 \theta=6.99^{\circ}$ and $2 \theta=7.11^{\circ}$ for Bentonite 34, indicating the basal spacing of $12.6 \mathrm{~A}$ and $12.4 \mathrm{~A}$ respectively.

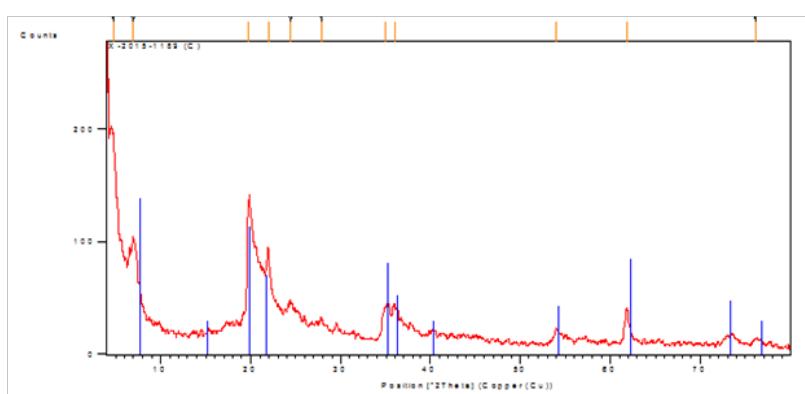

Figure 4A XRD patterns of Cloisite 20A.

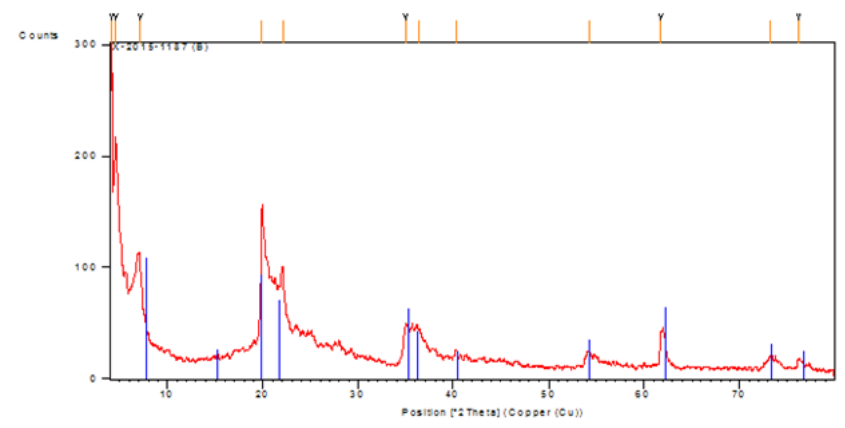

Figure 4B XRD patterns of Bentonite 34.

The XRD patterns of Poly (BA/MMA/AA)/Bentonite 34 composite at 5 wt. \%, however, is shown in Figure $4 \mathrm{c}$. The crystalline peak of 001 plane was observed with disappearance of other small $d_{001}$ peaks, implying that the intercalation of the $\mathrm{P}(\mathrm{BA} / \mathrm{MMA} / \mathrm{AA})$ into Bentonite 34 layers.

\section{Copolymers/nanocomposites thermal studies}

The thermal stability of the polymer blend in absence and presence of filling materials are done using TGA analysis Table 4, represent thermal parameters disclosure of the residual weight, degradation temperature at $10 \%$ weight loss $\left(\mathrm{Td}_{10}\right)$ and degradation temperature at $50 \%$ weight loss $\left(\mathrm{Td}_{50}\right)$ for the prepared copolymers and their composites with bentonite 34 and Cloisite 20. Figures 5a, 5b \& 5c represent clearly the thermo grams of the prepared copolymers and those nano bentonites added that reveal the following;

i. Copolymer blend of P (BA/MMA/AA) exhibit good thermal stability in absence of bentonite fillers.

ii. Copolymer blend of P (BA/MMA/AA)/Bentonite 34 and Cloisite 20 exhibit the same thermal behavior.

iii. The residual weight of the copolymer blend/nano bentonites is remarkably improved which affirms the role of thermal stability established through the bentonite basicity and its regular dispersion within the polymeric matrix.

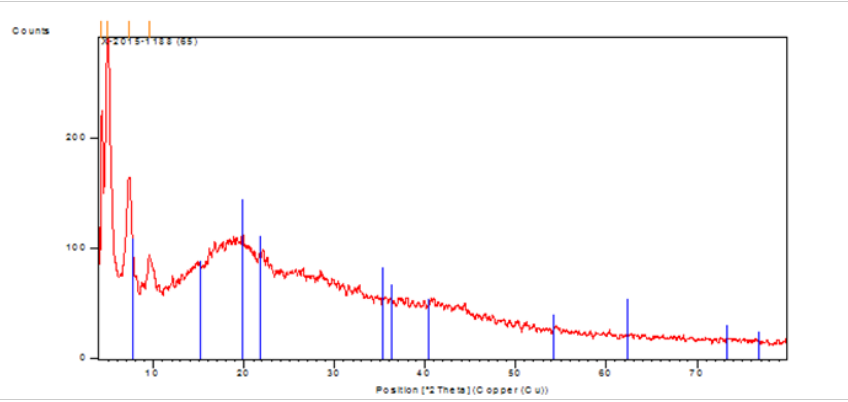

Figure 4C XRD patterns of Poly (BA/MMA/AA)/bentonite 34 composite.

Table 4 Residual weight and thermal degradation parameters of pure copolymers and bentonite composites

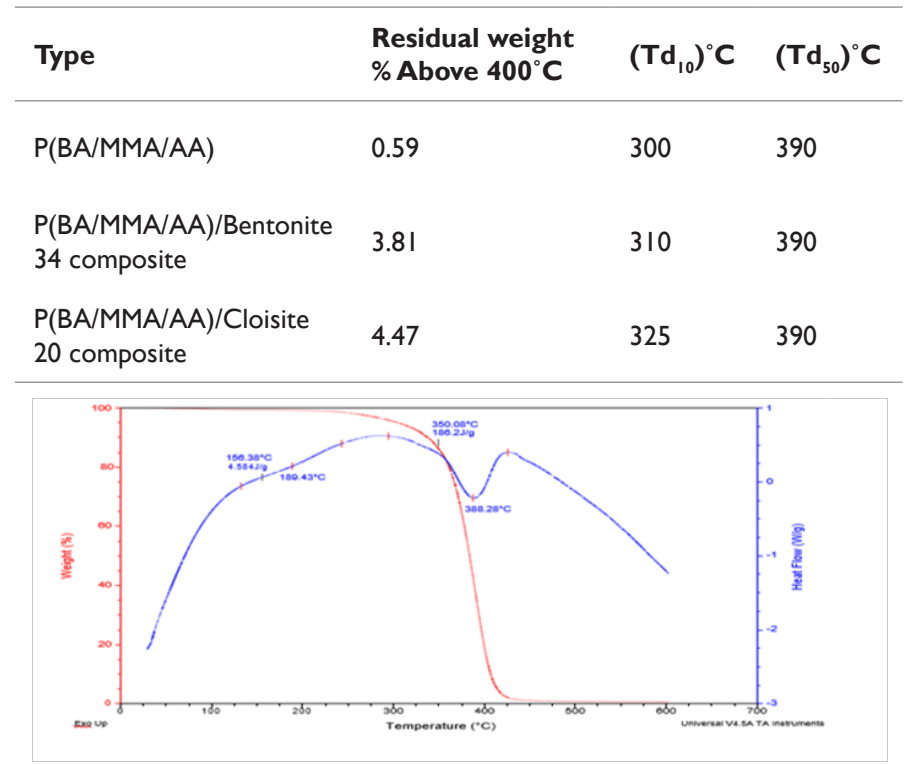

Figure 5A TGA of $P$ (BA/MMA/AA).

\section{Mechanical properties validation}

The mechanical properties of polymeric materials are most important parameters that determine the capability of material mold in suitable shape which induce in turn suitable specific and related features. The tensile strength and elongation at break for all polymer blend samples and composites have been measured and are given in Table 5 and Figures 6A, Figure 6B. 


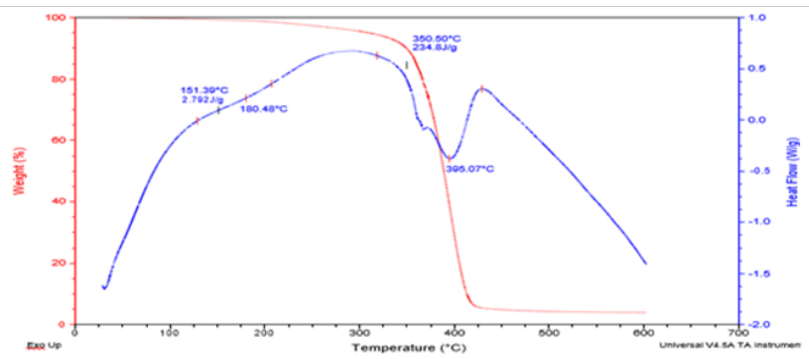

Figure 5B TGA of $\mathrm{P}(\mathrm{BA} / \mathrm{MMA} / \mathrm{AA})$ Bentonite 34 composite.

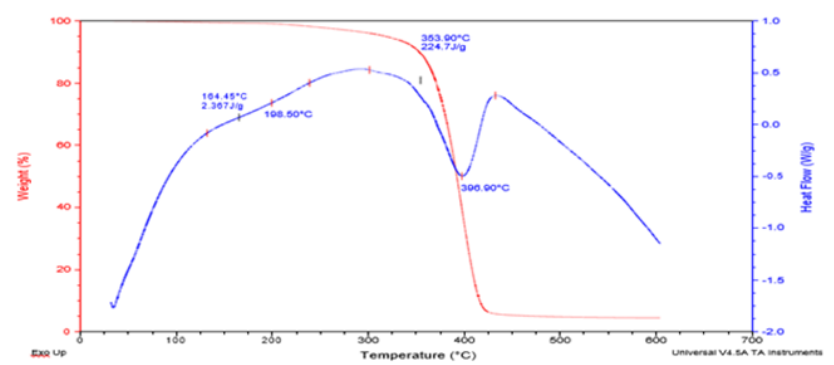

Figure 5C TGA of $\mathrm{P}(\mathrm{BA} / \mathrm{MMA} / \mathrm{AA})$ Cloisite 20 composite.

Table 5 Effect of Bentonite 34 and Cloisite 20 on the mechanical properties of BA/MMA/AA polymer blend

\begin{tabular}{lllll}
\hline \multirow{2}{*}{$\begin{array}{l}\text { Filler } \\
\text { ratio }\end{array}$} & \multicolumn{2}{l}{ Bentonite 34} & \multicolumn{2}{l}{ Cloisite 20 A } \\
\cline { 2 - 5 } & $\begin{array}{l}\text { Tensile } \\
\text { strength } \\
\left(\mathbf{K g} / \mathbf{c m}^{2}\right)\end{array}$ & $\begin{array}{l}\text { Elongation } \\
\text { at break }(\%)\end{array}$ & $\begin{array}{l}\text { Tensile } \\
\text { strength }\end{array}$ & $\begin{array}{l}\text { Elongation } \\
\text { at break (\%) }\end{array}$ \\
\hline- & 140 & 250 & $\left(\mathbf{K g} / \mathbf{c m}^{2}\right)$ & \\
\hline $1 \%$ & 142 & 264 & 140 & 250 \\
$3 \%$ & 161 & 275 & 141 & 260 \\
$5 \%$ & 177 & 255 & 162 & 273 \\
$7 \%$ & 159 & 238 & 175 & 260 \\
$10 \%$ & 146 & 222 & 161 & 235 \\
\hline
\end{tabular}

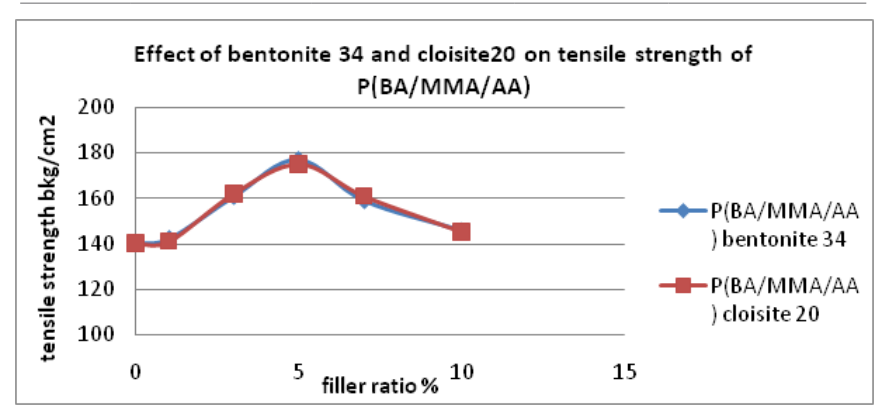

Figure 6A Effect of Bentonite 34 and Cloisite 20 on tensile strength of $\mathrm{P}(\mathrm{BA} /$ MMA/AA).

As detected, in absence of bentonite fillers the tensile strength of the copolymer BA/MMA/AA is $140 \mathrm{~kg} / \mathrm{cm}^{2}$ with measured elongation at break of $250 \%$. This is indicating that this composition is suitable to produce a polymeric material that can be suitable for cable insulators or sheathing, according to IEC 60502 and BS7655 section 6.1. Upon loading 1-5 wt. \% of bentonites filling material a considerable improvement in the mechanical properties was noticed which may be attributed to homogeneous dispersion of the filler within the polymeric matrix due to a probable conjugation and electrostatic attractions between polymer chains and the silicate layers. While at high filler concentration, poor dispersion and silicates particles agglomeration could have probably decreased the cohesive forces between polymer chains.

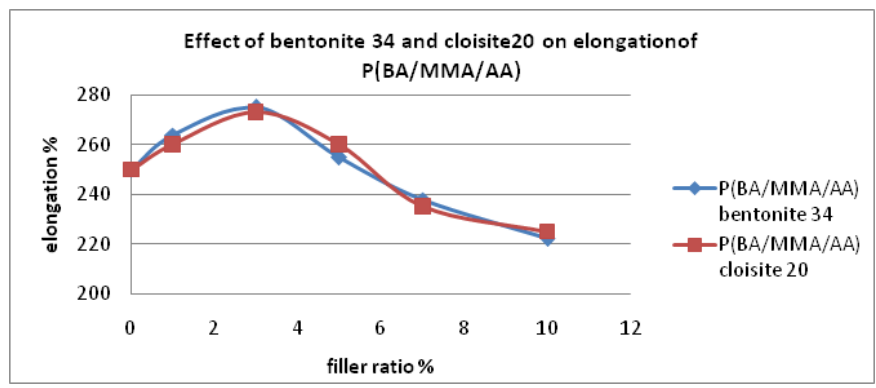

Figure 6B Effect of bentonite 34 and cloisite20 on elongation of P (BA/ MMA/AA).

\section{Shore hardness D}

Shore hardness D is a measure of the resistance of hard polymer material to penetration of a spring-loaded needle-like indenter. Shore hardness value may vary in the range from 0 to 100 . The maximum hardness value 100 corresponds to zero penetration while zero value corresponds to minimum shore hardness (2.5-2.54 mm penetration).

Upon measuring the shore hardness for all the samples, Table 6 and Figure 7, it is evident that the polymer blend offers a shore hardness of 53.5 , which is nearly the same value observed when adding bentonite filling material. Such observation indicates that the additions of bentonite 34 or Cloisite 20 silicate particle were not permitted to penetrate within the polymeric chains to influence the alteration of its stiffness. Accordingly, the composite is then still applicable for sheathing materials according to the cable specification HD 620.

Table 6 Effect of filling materials on Shore Hardness D after 15 second of the polymer blend

\begin{tabular}{lll}
\hline \multirow{2}{*}{ Filler ratio } & \multicolumn{2}{l}{ BA/MMA/AA blend } \\
\cline { 2 - 3 } & Bentonite 34 & Cloisite 20 \\
\hline- & 53.5 & 53.5 \\
$1 \%$ & 54 & 54 \\
$3 \%$ & 54 & 54 \\
$5 \%$ & 54 & 54 \\
$7 \%$ & 54 & 54 \\
$10 \%$ & 54 & 54 \\
\hline
\end{tabular}

\section{Density measurements}

The density of all polymer blend samples has been measured and given in Table 7 and Figure 8. As shown, the density increased gradually as the percentage of the filler material increased. So, according to cable specifications (ASTM D1248-98), these blends can be used as sheathing or insulators for electric cables. 


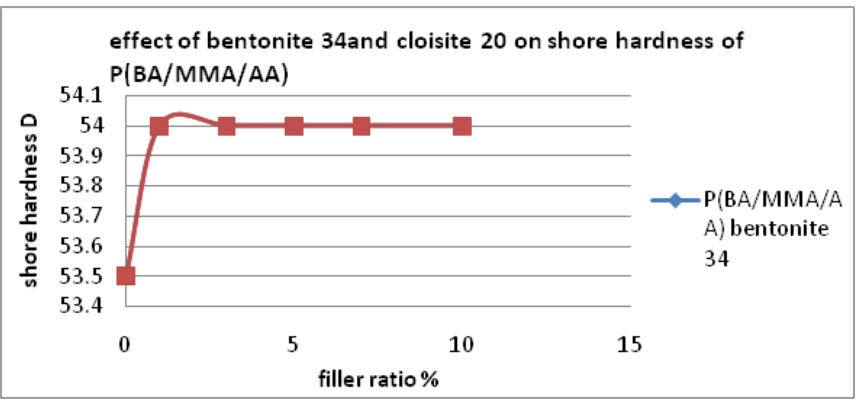

Figure 7 Effect of Bentonite 34and Cloisite 20 on shore hardness of $P(B A$ MMA/AA).

Table 7 Effect of filling materials on the density $(\mathrm{g} / \mathrm{cm} 3)$ of the polymer blends

\begin{tabular}{lll}
\hline \multirow{2}{*}{ Filler ratio } & \multicolumn{2}{l}{ BA/MMA/AA blend } \\
\cline { 2 - 3 } & Bentonite 34 & Cloisite 20 \\
\hline- & 1.12 & 1.12 \\
$1 \%$ & 1.125 & 1.126 \\
$3 \%$ & 1.142 & 1.14 \\
$5 \%$ & 1.145 & 1.144 \\
$7 \%$ & 1.151 & 1.15 \\
$10 \%$ & 1.156 & 1.155 \\
\hline
\end{tabular}

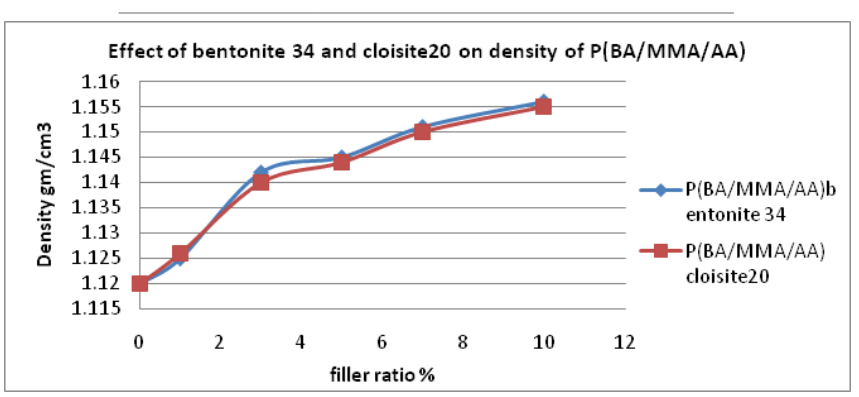

Figure 8 Effect of bentonite 34 and cloisite 20 on density of $P(B A / M M A / A A)$.

\section{Electrical properties}

The electrical property in term of volume resistivity and electric capacity is a one of the most important parameter for the polymeric material especially if it is used as an insulator or sheathing for the electrical cables.

The volume resistivity and electric capacity of different samples were measured and are given in Tables $8 \& 9$ and Figures 9A, Figure 9B. As shown, the volume resistivity and electric capacity of the three polymer blends are acceptable according to cable specifications data, IEC 60502 and ASTM D1248-98. Upon addition of Bentonite 34 or Cloisite 20 to the polymer blends an improvement to both the volume resistivity and the electric capacity properties were observed. This behavior can be attributed to the presence of nanofiller materials may affects the space charge accumulation in polymer matrix.

\section{Melt Flow Index}

Melt flow index is a measure of how many grams of a polymer flow through the die in ten minutes. It is an important parameter that is considered crucial during the fabrication process especially if it is used as insulator or sheathing for the electric cables. The melt flow index was measured for all samples, Table 10 and Figure 10. According to ASTM D 1248-98 categories 3, 4, and 3 respectively, the three blends are considered feasible for producing sheathing or insulating materials even in presence of bentonite filling materials at the studied weight ratios.

Table 8 Effect of filling material on the Volume Resistivity $(\Omega \mathrm{cm})$ of the polymer blends

\begin{tabular}{lll}
\hline Filler ratio & \multicolumn{2}{l}{ BA/MMA/AA blend } \\
\cline { 2 - 3 } & Bentonite 34 & Cloisite 20 \\
\hline- & $1.2 \times 10^{14}$ & $1.2 \times 10^{14}$ \\
$1 \%$ & $1.5 \times 10^{14}$ & $1.44 \times 10^{14}$ \\
$3 \%$ & $2.0 \times 10^{14}$ & $1.9 \times 10^{14}$ \\
$5 \%$ & $2.3 \times 10^{14}$ & $2.25 \times 10^{14}$ \\
$7 \%$ & $3.0 \times 10^{14}$ & $2.85 \times 10^{14}$ \\
$10 \%$ & $3.2 \times 10^{14}$ & $3.13 \times 10^{14}$ \\
\hline
\end{tabular}

Table 9 Effect of filling material on the Electrical Capacity $\left(\mathrm{PF}^{\mathrm{F}}\right)$ of the polymer blends

\begin{tabular}{lll}
\hline \multirow{2}{*}{ Filler ratio } & \multicolumn{2}{l}{ BA/MMA/AA blend } \\
\cline { 2 - 3 } & Bentonite 34 & Cloisite 20 \\
\hline- & 100 & 100 \\
$1 \%$ & 134 & 135 \\
$3 \%$ & 144 & 143 \\
$5 \%$ & 147 & 150 \\
$7 \%$ & 162 & 161 \\
$10 \%$ & 123 & 120 \\
\hline
\end{tabular}

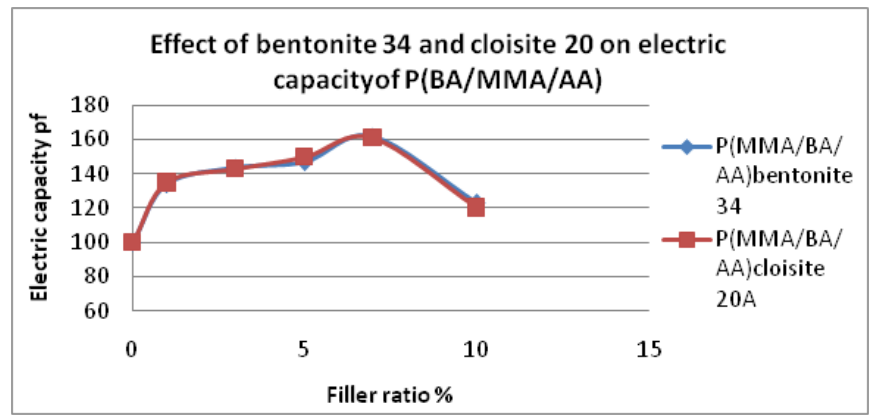

Figure 9A Effect of bentonite 34 and cloisite20 on electric capacity of $\mathrm{P}(\mathrm{BA} /$ $M M A / A A)$.

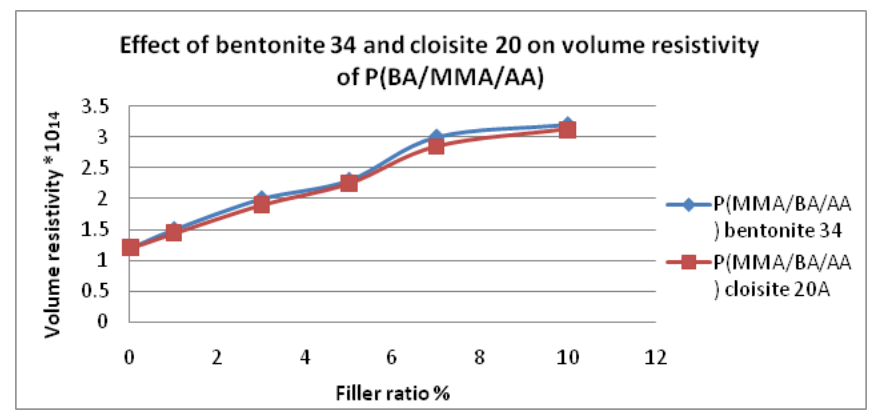

Figure 9B Effect of bentonite 34 and cloisite 20 on volume resistivity of $\mathrm{P}(\mathrm{BA} /$ MMA/AA). 
Table 10 Effect of filling material on the Melt Flow Index $(\mathrm{g} / 10 \mathrm{~min})$ of the polymer blends

\begin{tabular}{lll}
\hline \multirow{2}{*}{ Filler ratio } & \multicolumn{2}{l}{ BA/MMAAA blend } \\
\cline { 2 - 3 } & Bentonite 34 & Cloisite 20 \\
\hline $1 \%$ & 1.4 & 1.4 \\
$3 \%$ & 1.39 & 1.4 \\
$5 \%$ & 1.38 & 1.37 \\
$7 \%$ & 1.2 & 1.22 \\
$10 \%$ & 1.2 & 1.21 \\
\hline
\end{tabular}

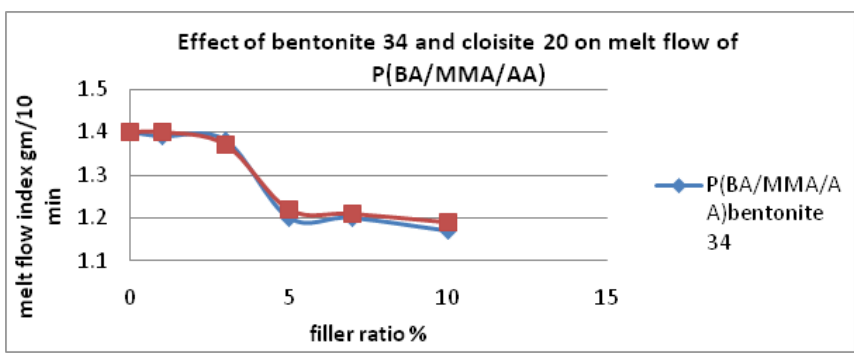

Figure 10 Effect of Bentonite 34 and Cloisite 20 on melt flow of $\mathrm{P}(\mathrm{BA} / \mathrm{MMA}$ AA).

\section{Sun light effect and aging}

All samples were subjected to sun light radiation for different time periods up to 180 days. The physico-mechanical properties of the aged samples were determined and the obtained results are presented in Tables $11 \& 12$ and Figures 11A, Figures 11B.

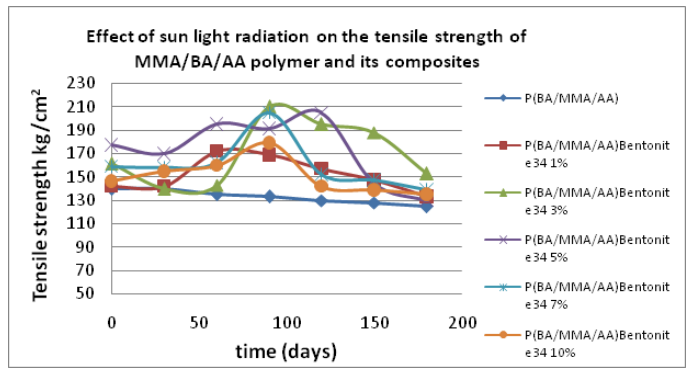

Figure I IA Effect of sun light radiation on tensile strength of the $P(B A /$ MMA/AA) and its composites.

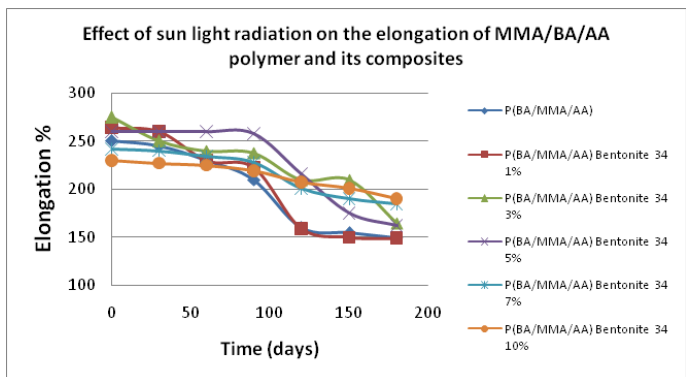

Figure I I B Effect of sun light radiation on elongation of the $P(B A / M M A / A A)$ and its composites.

Table I I Effect of sun light radiation on tensile strength of the BA/MMA/AA polymer and its bentonite 34 composites

\begin{tabular}{|c|c|c|c|c|c|c|}
\hline $\begin{array}{l}\text { Aging time } \\
\text { (Days) }\end{array}$ & Polymer & $\begin{array}{l}\text { Polymer + } \\
\text { bentonite34 I\% }\end{array}$ & $\begin{array}{l}\text { Polymer + } \\
\text { bentonite34 3\% }\end{array}$ & $\begin{array}{l}\text { Polymer + } \\
\text { bentonite34 5\% }\end{array}$ & $\begin{array}{l}\text { Polymer + } \\
\text { bentonite34 7\% }\end{array}$ & $\begin{array}{l}\text { Polymer + } \\
\text { bentonite34 10\% }\end{array}$ \\
\hline 0 & 140 & 142 & 161 & 177 & 159 & 146 \\
\hline 30 & 140 & 142 & 140 & 170 & 158 & 155 \\
\hline 60 & 135 & 172 & 143 & 195 & 162 & 160 \\
\hline 90 & 133 & 169 & 210 & 191 & 205 & 179 \\
\hline 120 & 130 & 157 & 195 & 205 & 152 & 142 \\
\hline 150 & 128 & 147 & 188 & 145 & 147 & 139 \\
\hline 180 & 125 & 133 & 153 & 130 & 139 & 135 \\
\hline
\end{tabular}

Table 12 Effect of sun light radiation on elongation of the BA/MMA/AA polymer and its composites

\begin{tabular}{|c|c|c|c|c|c|c|}
\hline $\begin{array}{l}\text { Aging time } \\
\text { (days) }\end{array}$ & Polymer & $\begin{array}{l}\text { Polymer + } \\
\text { bentonite34 (1\%) }\end{array}$ & $\begin{array}{l}\text { Polymer + } \\
\text { bentonite34 (3\%) }\end{array}$ & $\begin{array}{l}\text { Polymer + } \\
\text { bentonite34 (5\%) }\end{array}$ & $\begin{array}{l}\text { Polymer + } \\
\text { bentonite34 (7\%) }\end{array}$ & $\begin{array}{l}\text { Polymer }+ \\
\text { bentonite34 (10\%) }\end{array}$ \\
\hline 0 & 250 & 264 & 275 & 260 & 242 & 230 \\
\hline 30 & 245 & 260 & 250 & 260 & 240 & 227 \\
\hline 60 & 230 & 230 & 240 & 260 & 234 & 225 \\
\hline 90 & 210 & 223 & 238 & 258 & 228 & 219 \\
\hline 120 & 160 & 159 & 210 & 216 & 201 & 207 \\
\hline 150 & 155 & 150 & 210 & 175 & 190 & 201 \\
\hline 180 & 150 & 149 & 165 & 162 & 185 & 190 \\
\hline
\end{tabular}


As observed from the above data, stiffening of the polymeric composite is noticed upon exposure to sun light up to 180 days especially at filler concentration of $5 \%$. Elevation of the mechanical parameters was observed up till a 100 day of exposure then depreciation started to be influenced due to probable polymeric chains degradation and volatilization of smaller molecules that leads to filler material wt. \% increase comparatively and therefore affecting the mechanical parameters negatively.

\section{Conclusion}

The present work investigated the possibility of using the copolymerization of some acrylic monomers in presence of different ratio of organically treated bentonite and its applicability as a halogen free cables insulator. The following conclusions are derived:

a. Upon copolymerization of some acrylic monomers in presence of the bentonite fillers, the polymeric matrix was proved to offer its polymeric matrix as a good host to allocate the bentonite nano particles in a simulated intercalated layer rather than an exfoliated pattern.

b. The thermogravimetric studies affirmed that the residual weight of the copolymer blend/nano bentonites is remarkably improved which affirms the role of thermal stability established through the bentonite and its regular dispersion within the polymeric matrix.

c. The copolymer composite offered still valid values with regard to the melt flow index and mechanical properties according to related standards.

\section{Acknowledgements}

Chemical structural and microstructure features have partially been supported by the central lab of the faculty of science, AinShams University, Cairo, thanks also to the research and development department of the Egyptian company for plastic industries (El- Sewedy Electric), $10^{\text {th }}$ of Ramadan city, Sharkia, Cairo while density, melt flow, mechanical and electrical measurements were all conducted.

\section{Conflict of interest}

The author declares no conflict of interest.

\section{References}

1. Jocteur R. Influence of surface and internal defects of polyethylene electrical routine test on VHV cables. IEEE Trans. 1977;96(2).

2. Harper, Charles A. Handbook of Plastic Processes. USA: John Wiley \& Sons; 2005.

3. Brandrup J, Immergut EH. Poly (butyl acrylate). In: Polymer Hand book. 3rd ed. New York: Wiley; 1989. p. 428-429.

4. Zhiyi Z, Ning Z, Wei W, et al. Synthesis, characterization and application of poly (butyl acrylate-co-methyl methacrylate)/clay nanocomposites via emulsion polymerization. Surface Science and Catalysis. 2005;529 p.

5. Alexandre M, Dubois P. Polymer-layered silicate nanocomposites: preparation, properties and uses of a new class of materials. Mater $\mathrm{Sci}$ Eng. 28(1-2):1-63.

6. Guo Z, Henry LL, Palshin V, et al. Synthesis of poly(methyl methacrylate) stabilized colloidal zero-valence metallic nanoparticles. J Mater Chem. 2006;16:1772-1777.

7. Wu L, Wang M, Zhang X, et al. Organic montmorillonite modified polyacrylate nanocomposite by emulsion polymerization. IranPolym J. 2009;18(9):703-712.

8. Silva AA, Dahmouche K, Soares BG. The effect of addition of acrylic acid and thioglycolic acid on the nanostructure and thermal stability of PMMA montmorillonite nanocomposites. Appl Clay Sci. 2010;47(34):414-420.

9. Li H, Wang L, Song G, et al. Study of NBR/PVC/OMMT nanocomposites prepared by mechanical blending. Iran Polym J. 2010;19(1):39-46.

10. Khosrokhavar R, Naderi G, Bakhshandeh GR, et al. Effect of processing parameters on PP/EPDM/Organoclay nanocomposites using Taguchi analysis method. Iran Polym J. 2011;20: 41-53.

11. Saeedi M, Ghasemi I, Karrabi M. Thermal degradation of poly (vinyl chloride): effect of nanoclay and low density polyethylene content. Iran Polym J. 2011;20:423-432.

12. Pospisil M, Capkova P, Merinska D, et al. Structure Analysis of montmorillonite intercalated with cetylpyridinium and cetyltrimethylammonium: molecular simulations and XRD analysis. $J$ Colloid Interface Sci. 1988;236 (1):127-131.

13. Njopwouo D, Roques G, Wandji R. A contribution to the study of the catalytic action of clays on the polymerization of styrene: II. Reaction mechanism. Clay minerals. 1988;23:35-43. 